\title{
Lung function in adults with cystic fibrosis at altitude: impact on air travel
}

\author{
R. Fischer*, S.M. Lang*\#, K. Brückner*, H-X. Hoyer*, S. Meyer", \\ M. Griese and R.M. Huber*
}

ABSTRACT: Current guidelines for air travel state that patients with chronic respiratory diseases are required to use oxygen if their in-flight arterial oxygen tensions $\left(\mathrm{Pa}, \mathrm{O}_{2}\right)$ drop below $6.6 \mathrm{kPa}$. This recommendation may not be strictly applicable to cystic fibrosis patients, who may tolerate lower $\mathrm{Pa}, \mathrm{O}_{2}$ for several hours without clinical symptoms.

Lung function, symptoms, blood gas levels and signs of pulmonary hypertension were studied in 36 cystic fibrosis patients at altitudes of $530 \mathrm{~m}$ and, after $7 \mathrm{~h}, 2,650 \mathrm{~m}$. A hypoxia inhalation test (inspiratory oxygen fraction $\mathbf{0 . 1 5}$ ) was performed at low altitude in order to predict high-altitude hypoxaemia.

Median $\mathrm{Pa}, \mathrm{O}_{2}$ dropped from $9.8 \mathrm{kPa}$ at low altitude to $7.0 \mathrm{kPa}$ at high altitude. Mild exercise at a workload of $30 \mathrm{~W}$ further decreased $\mathrm{Pa}, \mathrm{O}_{2}$. Two-thirds of all patients exhibited $\mathrm{Pa}, \mathrm{O}_{2}$ of $<6.6 \mathrm{kPa}$ during exercise and, except for one patient, were asymptomatic. Patients were significantly less obstructed at an altitude of $2,650 \mathrm{~m}$. Low forced expiratory volume in one second at baseline was associated with a low $\mathrm{Pa}_{2} \mathrm{O}_{2}$ at altitude.

It is concluded that cystic fibrosis patients with baseline arterial oxygen tensions of $>8.0 \mathrm{kPa}$ safely tolerate an altitude of $2,650 \mathrm{~m}$ for several hours under resting conditions. The risk assessment of low in-flight oxygenation should encompass the whole clinical situation of cystic fibrosis patients, with special attention being paid to the presence of severe airway obstruction.

KEYWORDS: Air travel, cystic fibrosis, exercise, guidelines, hypoxia

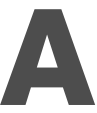
ccording to US federal regulations, passenger cabins of commercial aircraft at cruising altitude are pressurised equivalent to an altitude not exceeding 2,438 m $(8,000 \mathrm{ft})$ [1]. During domestic and international flights, considerable variations in cabin pressure can be found, equivalent to an altitude range of $0-2,717 \mathrm{~m} \mathrm{[2]}$. Breathing air at a pressure equivalent to an altitude of $2,438 \mathrm{~m}$ is equivalent to a reduction in oxygen concentration to $15.1 \%$. Although healthy subjects can undoubtedly tolerate this condition, it may cause severe hypoxaemia in patients with pulmonary disease.

The significantly prolonged life expectancy and much improved quality of life in adult patients with cystic fibrosis (CF) enable these patients to participate in every aspect of modern life, including air tourism. Today, even patients with advanced lung disease travel to remote holiday or rehabilitation locations, with a maximum time of up to $18 \mathrm{~h}$ spent on long international flights. The treating physicians are increasingly frequently confronted with the question as to whether an individual CF patient meets the requirements of these long-haul flights.
The current guidelines of the American Thoracic Society (ATS) and British Thoracic Society (BTS) recommend that an arterial oxygen tension $\left(\mathrm{Pa}, \mathrm{O}_{2}\right)$ of $>6.6 \mathrm{kPa}(>50 \mathrm{mmHg})$ be maintained during flight in patients with obstructive lung disease [3, 4]. For all patients with a sea-level arterial oxygen saturation $\left(\mathrm{Sa}_{\mathrm{a}} \mathrm{O}_{2}\right)$ of $<92 \%$ or $\mathrm{Pa}, \mathrm{O}_{2}$ of $<9.30 \mathrm{kPa}(<70 \mathrm{mmHg})$, additional oxygen is recommended during flight. However, as stated in these guidelines, the value of $6.6 \mathrm{kPa}$ "appears purely arbitrary with no supporting evidence".

Owing to the current lack of sufficient data, many CF patients are denied access to overseas rehabilitation programmes or are required to request costly in-flight oxygen supply [5].

The aim of the present study was to test tolerance to low $\mathrm{Pa}_{1} \mathrm{O}_{2}$ at a high-altitude laboratory at $2,650 \mathrm{~m}$ in the German Alps in adult patients with $\mathrm{CF}$ and address the question of whether in-flight hypoxaemia could be predicted using a standard pre-flight evaluation. It was assumed that fitness to fly could be best predicted in patients with CF with varying severity of lung disease during exposure to high altitude for a
AFFILIATIONS

*Dept of Medicine, Division of Pneumology, Clinic for Internal Medicine, and

-Dept of Paediatrics, Dr. von Hauner's Children's Hospital, University of Munich, Munich, and \#Clinic Bad Reichenhall, Bad Reichenhall, Germany.

CORRESPONDENCE

R. Fischer

Pneumology

Medizinische Klinik Innenstadt University of Munich Ziemssenstr. 1

D-80336 München Germany

Fax: 498951604905

E-mail: rainald.fischer@med.unimuenchen.de

Received:

July 242004

Accepted after revision:

November 062004

\section{SUPPORT STATEMENT}

This study was supported by the Bavarian Ministry of Economic Affairs, Infrastructure, Transport and Technology, Munich; Radiometer, Inc., Munich; and Viasys Healthcare, Inc., Höchberg (all Germany). 
duration of time simulating a long-haul flight of $7 \mathrm{~h}$. In addition, the investigations recommended by the guidelines were carried out, including a hypoxic inhalation test with an inspiratory oxygen fraction $\left(\mathrm{FI}, \mathrm{O}_{2}\right)$ of 0.15 , in order to determine possible pre-flight variables predicting in-flight hypoxaemia.

\section{METHODS}

\section{Study population}

Adult CF patients $(\mathrm{n}=36$ (21 male)) aged 19-47 yrs (mean $30.5 \mathrm{yrs}$ ) participated in the present study. The diagnosis of $\mathrm{CF}$ had been confirmed both clinically and genetically. All of the patients were seen routinely every 3 months in the care outpatient clinics for adult CF patients, at either the Clinic for Internal Medicine or the Dr. von Hauner's Children's Hospital of the University of Munich (Munich, Germany). In the order of these visits, patients were asked to participate in the study. Inclusion criteria were a resting $\mathrm{Pa}_{1} \mathrm{O}_{2}$ of $>8.0 \mathrm{kPa}$ (60 mmHg) or $\mathrm{Sa}_{1} \mathrm{O}_{2}$ of $>88 \%$ during a stable phase of the disease. Patients with clinically apparent cor pulmonale, alveolar hypoventilation (arterial carbon dioxide tension $\left(\mathrm{Pa}, \mathrm{CO}_{2}\right)$ of $\left.>6.0 \mathrm{kPa}\right)$, pulmonary exacerbation, acute pneumothorax or other severe concomitant diseases were excluded. The presence of diabetes or pathological glucose tolerance was accepted. All of the present study subjects lived at altitudes of 386-758 m (median $518 \mathrm{~m}$ (SD $99 \mathrm{~m}$ )), making them a comparable cohort.

\section{Study design}

The present prospective observational study evaluated fitness to fly in adult CF patients. Baseline measurements were carried out at an altitude of $530 \mathrm{~m}$ (Munich) 2 weeks prior to the measurements at an altitude of 2,650 m (Environmental Research Station Schneefernerhaus (UFS), Zugspitze, Germany). The local ethics committee approved the study protocol. All patients gave written informed consent.

\section{Laboratory tests}

Baseline values were assessed during routine visits to the specialty care outpatient clinics in Munich $(530 \mathrm{~m})$. Spirometry, body plethysmography and transcutaneous pulse oximetry were performed in all patients. Blood gas analyses (from the arterialised ear lobe) were performed in $26(72 \%)$ patients and a hypoxia inhalation test (HIT) in $23(64 \%)$. During the routine visits of patients from the Dr. von Hauner's Children's Hospital, blood gas analysis from the arterialised ear lobe was not included in the quarterly follow-up. These patients agreed to participate in the present study under the condition that only two blood samples were drawn at altitude. Therefore, baseline blood gas data and HIT results are absent for these 10 patients. Owing to scheduling problems, three patients could not be measured within 14 days after the mountain exposure and the HIT was not performed.

Lung function tests, including spirometry and body plethysmography, were performed according to ATS criteria using the Jaeger MasterLab (Viasys Healthcare, Inc., Höchberg, Germany) by trained technicians [6]. Pulmonary function test results (except for airway resistance) were expressed as a percentage of the predicted value: forced expiratory volume in one second (FEV1), forced vital capacity (FVC), maximal expiratory flow when $25 \%$ of the FVC remains to be exhaled (MEF25), maximal expiratory flow when $75 \%$ of the FVC remains to be exhaled (MEF75), Tiffeneau index (FEV1/FVC), airway resistance, residual volume (RV), total lung capacity (TLC), and intrathoracic gas volume (ITGV) [7]. $\mathrm{Sa}_{1} \mathrm{O}_{2}$ was measured using a standard transcutaneous pulse oximeter with the patient breathing quietly at rest for $\geqslant 2 \mathrm{~min}$. Doppler echocardiography (SonoAce 9900; Medison, Inc., Seoul, Korea), performed in 17 patients, detected quantifiable tricuspid valve regurgitation in order to estimate right ventricular peak systolic pressure in 12 patients [8].

The high-altitude values were obtained at UFS, located $300 \mathrm{~m}$ below the top of Germany's highest mountain, Zugspitze, at $2,650 \mathrm{~m}$ above sea level. When the patients agreed to participate, the date of the study day was arranged between days 12 and 14 after the baseline measurements. The research station is equipped with a standard lung function laboratory, including facilities for spirometry and body plethysmography (MasterLab), pulse oximetry, exercise testing using a cycle ergometer and blood gas analysis (ABL5; Radiometer, Copenhagen, Denmark; Oxycon alpha; Viasys Healthcare, Inc.). The MasterLab, ABL5 and Oxycon alpha were adjusted daily to current atmospheric pressure. For technical reasons, exercise blood gas levels could not be analysed at high altitude in one subject. In the subgroup of patients indicated above, Doppler echocardiography was carried out at low altitude and after $4 \mathrm{~h}$ of stay at UFS.

All patients reached Eibsee, Germany (altitude 1,008 m), the starting point of the cogwheel railway, by car or train on the morning of the altitude study day. The cogwheel train reached Sonnalpin (Germany), at an altitude of 2,588 m, after $50 \mathrm{~min}$. From there, the journey was continued by cable car to UFS. All patients stayed at the high-altitude laboratory for $7 \mathrm{~h}$. The first measurements were performed shortly after arrival at UFS and the second measurements before departure. The time interval between the two sets of altitude measurements was $6 \mathrm{~h}$. Exercise testing was performed with a constant workload of $30 \mathrm{~W}$ for $5 \mathrm{~min}$ before departure. Symptoms were recorded in accordance with the Lake Louise Scoring System (LLSS) for acute mountain sickness [9]. Level walking was allowed for no more than $150 \mathrm{~m}$, and all patients were encouraged to sit during the stay at UFS. None of the patients slept during the study period. For safety reasons, patients were equipped with a portable pulse oximeter before entering the cogwheel train, throughout the high-altitude study and until their return to the car or train in Eibsee in the late afternoon. $\mathrm{Sa}, \mathrm{O}_{2}$ measurements were performed hourly or when clinically indicated.

\section{Hypoxia inhalation test}

After a 2-week interval from the high-altitude study, the patients might participate voluntarily in the HIT.

The patients breathed a gas mixture consisting of $15 \%$ oxygen and $85 \%$ nitrogen at rest from a reservoir balloon with a volume of $10 \mathrm{~L}$ for $15 \mathrm{~min}$. The gas mixture was given via a non-rebreathing valve with a tight-fitting commercial continuous positive airway pressure nose mask. $\mathrm{Sa}_{1} \mathrm{O}_{2}$ was monitored throughout the hypoxic challenge. Blood was drawn from the arterialised ear lobe before and during the last minute of the test. 


\section{Data analysis}

It was planned to investigate $\geqslant 30$ patients in the present study, in order to allow for a sufficient range of lung disease severity and analyse possible predictive variables. The power of the present study to detect changes in blood gas levels was 1.0 due to the large differences between low and high altitude and between the results of the HIT. The study was not designed to detect changes in lung function parameters.

Data are expressed as median and range. The Wilcoxon signed-rank test with exact statistics was used to compare baseline and high-altitude values. Spearman's rank correlation coefficient was used to describe the relationship between baseline and high-altitude values or HIT results. Receiveroperating characteristic (ROC) curves, with sensitivity plotted against false positive rate (1-specificity), were used to compare the power of different baseline values to predict a $\mathrm{Pa}_{1} \mathrm{O}_{2}$ at an altitude of $<6.6 \mathrm{kPa}(<50 \mathrm{mmHg}$ ) at rest and during moderate exercise: the greater the predictive power the larger the area under the curve. In order to avoid a large number of false positive results, with the ensuing decrease in sensitivity, the cut-off values of baseline parameters resulting in a sensitivity of $\geqslant 75 \%$ and a specificity of $\geqslant 85 \%$ were listed [10]. A p-value of $<0.05$ was regarded as significant.

\section{RESULTS}

\section{Lung function at baseline}

Twenty patients were classified as having pulmonary disease of mild severity (FEV1 $>70 \%$ pred) and 11 patients had an FEV1 of $<50 \%$ pred at baseline. Eight patients showed a baseline $\mathrm{Pa}, \mathrm{O}_{2}$ of $<9.3 \mathrm{kPa}(<70 \mathrm{mmHg})$; the $\mathrm{FEV} 1$ of these patients ranged $27-90 \%$ pred.

When patients were stratified according to the BTS guidelines regarding fitness to fly, 16 patients were classified as not requiring in-flight oxygen $\left(\mathrm{Sa}_{\mathrm{a}} \mathrm{O}_{2}>95 \%\right)$, four should undergo pre-flight hypoxic challenge $\left(\mathrm{Sa}_{2} \mathrm{O}_{2}\right.$ 92-95\%; FEV1 $\left.<50 \%\right)$ and five would have required oxygen during the altitude exposure $\left(\mathrm{Sa}_{\mathrm{a}} \mathrm{O}_{2}<92 \%\right)$.

\section{Symptoms at high altitude}

All patients found the sojourn at the high-altitude laboratory to be comfortable and pleasant. The median \pm SD LLSS was $1.0 \pm 0.78$ at the end of the high-altitude stay (LLSS of 0 in 17 patients, 1 in 14 and 2 in 4, with a maximum possible LLSS of 15). The patient with the lowest $\mathrm{Pa}_{1} \mathrm{O}_{2}$ reported dizziness during exercise testing (LLSS 3). None of the patients experienced clinically relevant dyspnoea or cardiac palpitations.

\section{Lung function at high altitude}

Compared to baseline (table 1) and in contrast to previous studies [11, 12], a significant decrease in bronchial obstruction, measured using both forced spirometry and body plethysmography, was found together with an increase in TLC and ITGV at high altitude. RV increased by $>17 \%$, but this change did not reach significance. During the stay at high altitude, no further significant change in lung function was observed.

\section{Blood gas levels at high altitude}

$\mathrm{Pa}_{1} \mathrm{O}_{2}$ was significantly reduced at high altitude, with a slight decrease in $\mathrm{Pa}_{\mathrm{a}} \mathrm{CO}_{2}$ (table 1). $\mathrm{Sa}, \mathrm{O}_{2}$ dropped markedly and pulse rate increased. Mild exercise at $30 \mathrm{~W}$ induced a further drop in

\begin{tabular}{|c|c|c|c|}
\hline \multirow[t]{2}{*}{ TABLE 1} & \multicolumn{3}{|c|}{$\begin{array}{l}\text { Respiratory parameters at baseline }{ }^{\#} \text { and after } 1 \\
\text { at an altitude of } 2,650 \mathrm{~m}\end{array}$} \\
\hline & Baseline & $2,650 \mathrm{~m}$ & p-value \\
\hline FEV $1 \%$ pred & $66(26-107)$ & $69(30-115)$ & $<0.001$ \\
\hline FVC \% pred & $85(51-108)$ & $88(47-119)$ & 0.02 \\
\hline Tiffeneau index & $65.7(34.0-89.0)$ & $68.0(44.0-86.0)$ & 0.001 \\
\hline PEF \% pred & $72(24-112)$ & $88(42-132)$ & $<0.001$ \\
\hline MEF25 \% pred & $19(0-75)$ & $28(8-76)$ & $<0.001$ \\
\hline Raw $\mathrm{kPa} \cdot \mathrm{s}^{-1} \cdot \mathrm{L}^{-1}$ & $0.4(0.1-1.1)$ & $0.32(0.16-1.10)$ & 0.009 \\
\hline ITGV \% pred & 117 (63-196) & $132(70-194)$ & $<0.001$ \\
\hline TLC \% pred & $105(66-131)$ & 109 (66-142) & 0.032 \\
\hline RV \% pred & 152 (79-286) & $188(68-341)$ & 0.14 \\
\hline $\mathrm{Pa}, \mathrm{O}_{2} \mathrm{kPa}$ & $9.8(8.0-13.0)$ & $7.0(5.3-10.5)$ & $<0.001$ \\
\hline $\mathrm{Pa}, \mathrm{CO}_{2} \mathrm{kPa}$ & $5.1(4.4-6.0)$ & $4.7(3.7-6.0)$ & $<0.001$ \\
\hline $\mathrm{Sa}, \mathrm{O}_{2} \%$ & 95 (89-99) & $90(66-98)$ & $<0.001$ \\
\hline Pulse rate & $83(66-110)$ & $84(66-118)$ & 0.059 \\
\hline
\end{tabular}

Data are presented as median (range), unless otherwise stated. FEV1: forced expiratory volume in one second; FVC: forced vital capacity; PEF: peak expiratory flow; MEF25: maximal expiratory flow when $25 \%$ of the FVC remains to be exhaled; Raw: airway resistance; ITGV: intrathoracic gas volume; TLC: total lung capacity; $\mathrm{RV}$ : residual volume; $\mathrm{Pa}, \mathrm{O}_{2}$ : arterial oxygen tension; $\mathrm{Pa}_{1} \mathrm{CO}_{2}$ : arterial carbon dioxide tension; $\mathrm{Sa}_{\mathrm{O}_{2}}$ : arterial oxygen saturation; \% pred: percentage of the predicted value. ${ }^{\#}$ : (530 m above sea level); ${ }^{\bullet}$ : FEV1/FVC.

$\mathrm{Pa}_{2} \mathrm{O}_{2}$; the lowest value measured was $4.4 \mathrm{kPa}(33 \mathrm{mmHg})$ (table 2). Between the first and second measurements, there was no significant change in $\mathrm{Pa}_{1} \mathrm{O}_{2}$ or $\mathrm{Pa}_{\mathrm{a}} \mathrm{CO}_{2}$.

Immediately after arrival at altitude, $33.3 \%$ of all patients had $\mathrm{Pa}_{1} \mathrm{O}_{2}$ of $<6.6 \mathrm{kPa}$ (50 mmHg). During mild exercise at $30 \mathrm{~W}$, $67.5 \%$ of patients reached values of $<6.6 \mathrm{kPa}$. Four out of 20 patients with mild lung disease exhibited $\mathrm{Pa}_{2} \mathrm{O}_{2}$ of $<6.6 \mathrm{kPa}$ at the second measurement and 10 patients were below this limit during mild exercise. In the group of patients with severe pulmonary disease, $\mathrm{Pa}_{1} \mathrm{O}_{2}$ was $<6.6 \mathrm{kPa}$ in six of 11 subjects under resting conditions. During exercise, only one patient retained a $\mathrm{Pa}_{1} \mathrm{O}_{2}$ of $>6.6 \mathrm{kPa}$.

\section{Hypoxia inhalation test}

With inhalation of hypoxic air $\left(\mathrm{FI}, \mathrm{O}_{2} 0.15\right), \mathrm{Pa}_{1} \mathrm{O}_{2}$ was significantly reduced, with a concomitant fall in $\mathrm{Pa}_{2} \mathrm{CO}_{2}$ (table 3). The

\begin{tabular}{|c|c|c|c|c|}
\hline TABLE 2 & \multicolumn{4}{|c|}{$\begin{array}{l}\text { Blood gas levels and oxygen saturation at } 2,650 \mathrm{~m} \\
\text { after } 7 \mathrm{~h} \text { at rest and } 5 \mathrm{~min} \text { exercise at } 30 \mathrm{~W}\end{array}$} \\
\hline & Subjects $n$ & $7 \mathrm{~h}$ at rest & 5 min exercise & p-value \\
\hline $\mathrm{Pa}, \mathrm{O}_{2} \mathrm{kPa}$ & 35 & $6.9(5.3-9.6)$ & $6.3(4.4-9.2)$ & $<0.001$ \\
\hline $\mathrm{Pa}, \mathrm{CO}_{2} \mathrm{kPa}$ & 35 & $4.5(2.9-5.9)$ & $4.5(3.5-5.9)$ & 0.45 \\
\hline $\mathrm{Sa}, \mathrm{O}_{2} \%$ & 36 & $90(80-98)$ & $86(56-93)$ & $<0.001$ \\
\hline
\end{tabular}




\begin{tabular}{|c|c|c|c|c|}
\hline \multirow[t]{2}{*}{ TABLE 3} & \multicolumn{4}{|c|}{$\begin{array}{l}\text { Hypoxia inhalation test: blood gas levels and } \\
\text { oxygen saturation at } 530 \text { m before and after } \\
\text { inhalation of } 15 \% \text { oxygen for } 15 \text { min }\end{array}$} \\
\hline & Subjects n & Before & After & $p$-value \\
\hline $\mathrm{Pa}, \mathrm{O}_{2} \mathrm{kPa}$ & 23 & $9.6(7.4-12.0)$ & $6.9(5.5-8.2)$ & $<0.001$ \\
\hline $\mathrm{Pa}, \mathrm{CO}_{2} \mathrm{kPa}$ & 23 & $4.9(4.1-6.0)$ & $5.0(3.7-5.6)$ & 0.03 \\
\hline $\mathrm{Sa}, \mathrm{O}_{2} \%$ & 23 & $95(88-98)$ & 89 (82-94) & $<0.001$ \\
\hline
\end{tabular}

median drop in $\mathrm{Pa}_{\mathrm{a}} \mathrm{O}_{2}$ observed at high altitude was comparable to the results of the HIT (change in $\mathrm{Pa}_{1} \mathrm{O}_{2}$ between baseline and 2,650 m $3 \mathrm{kPa}$; change in $\mathrm{Pa}_{1} \mathrm{O}_{2}$ during HIT $2.8 \mathrm{kPa}$ ). However, the correlation coefficient for these two values was only $0.5(\mathrm{p}=0.018)$, suggesting a low predictive value of HIT results in individual patients.

\section{Cardiocirculatory parameters}

Estimated right ventricular peak systolic pressure increased significantly from $27.6(21-32) \mathrm{mmHg}$ at $530 \mathrm{~m}$ to $34.8(12-43)$ $\mathrm{mmHg}$ at $2,650 \mathrm{~m}(\mathrm{p}=0.003)$ [13]. Pulse rate increased moderately from baseline to altitude $(p=0.06)$ and increased further during mild exercise $(p<0.001)$.

\section{Correlations and receiver-operating characteristic curves}

The correlation coefficient of baseline $\mathrm{Pa}, \mathrm{O}_{2}$ with the $\mathrm{Pa}, \mathrm{O}_{2}$ after arrival at $2,650 \mathrm{~m}$ was $0.76(\mathrm{p}<0.001)$, contrasting with the correlation coefficient of the $\mathrm{Pa}_{\mathrm{a}} \mathrm{O}_{2}$ before and after the HIT $(\mathrm{r}=0.61, \mathrm{p}=0.002)$. The correlation between the difference in $\mathrm{Sa}_{1} \mathrm{O}_{2}$ at baseline and at $2,650 \mathrm{~m}$ and $\mathrm{Sa}_{1} \mathrm{O}_{2}$ before and after inhalation of an $\mathrm{FI}_{\mathrm{I}} \mathrm{O}_{2}$ of $15 \%$ was $0.299 \quad(\mathrm{p}=0.187)$. No significant correlation was found between right ventricular peak systolic pressure and $\mathrm{Pa}_{1} \mathrm{O}_{2}$ at altitude. There was no significant correlation between the altitude at which patients lived and $\mathrm{Pa}_{2} \mathrm{O}_{2}$ at altitude, either at rest or during moderate exercise.

Baseline parameters were analysed using ROC curves to predict $\mathrm{Pa}_{\mathrm{a}} \mathrm{O}_{2}$ at an altitude of $<6.6 \mathrm{kPa}$ at rest (table 4 , fig. 1) and during moderate exercise (table 5, fig. 2). Significant baseline predictors were $\mathrm{Pa}_{2} \mathrm{O}_{2}, \mathrm{FEV} 1, \mathrm{MEF} 75, \mathrm{MEF} 25, \mathrm{~Pa}_{2} \mathrm{O}_{2}$ after hypoxic challenge and $\mathrm{Sa}_{2} \mathrm{O}_{2}$.

Other spirometric and body plethysmographic variables, such as specific resistance, peak flow, FVC and maximal expiratory flow when $50 \%$ of the FVC remains to be exhaled, all contributed to the prediction of $\mathrm{Pa}, \mathrm{O}_{2}$ at high altitude, but did not improve the predictive power when added to the ROC curves.

\section{DISCUSSION}

Current recommendations for oxygen prescription for air travel are derived from the positive effects of oxygen supplementation on right heart function, respiratory muscle function and survival in patients with chronic hypoxaemia [14]. These effects rely, however, on long-term oxygen application for $\geqslant 15 \mathrm{~h} \cdot$ day $^{-1}$. It is less clear what effects short

\begin{tabular}{|c|c|c|c|c|c|}
\hline $\begin{array}{l}\text { Cor } \\
\text { the } \\
\text { at c } \\
\text { rec }\end{array}$ & $\begin{array}{l}\text { rison } \\
\text { dictic } \\
\text { de o } \\
\text { r-ope }\end{array}$ & $\begin{array}{l}\text { of differe } \\
\mathrm{n} \text { of an a } \\
<6.6 \mathrm{kP} \\
\text { rating che }\end{array}$ & $\begin{array}{l}\text { ht base } \\
\text { terial o } \\
\text { at res } \\
\text { racteris }\end{array}$ & $\begin{array}{l}\text { line paramete } \\
\text { kygen tension } \\
\text { t using } \\
\text { tic curves }\end{array}$ & $\begin{array}{l}\text { ers for } \\
\left(\mathrm{Pa}, \mathrm{O}_{2}\right)\end{array}$ \\
\hline & AUC & $95 \% \mathrm{Cl}$ & $\begin{array}{l}\text { Cut-off } \\
\text { value }\end{array}$ & $\begin{array}{c}\text { False-positive } \\
\text { rate } \%\end{array}$ & $p$-value \\
\hline MEF75 \% pred & 0.91 & $0.79-1.01$ & $<31$ & 9 & 0.01 \\
\hline FEV 1 \% pred & 0.89 & $0.77-1.01$ & $<48$ & 9 & 0.01 \\
\hline Tiffeneau index & 0.89 & $0.76-1.10$ & $<56$ & 9 & 0.01 \\
\hline MEF25 \% pred & 0.84 & $0.70-0.98$ & $<13.5$ & 17 & 0.004 \\
\hline $\mathrm{Pa}, \mathrm{O}_{2}$ baseline $\mathrm{kPa}$ & 0.86 & $0.71-1.00$ & $<9.5$ & 23 & 0.004 \\
\hline $\mathrm{Sa}, \mathrm{O}_{2}$ baseline $\%$ & 0.85 & $0.71-1.00$ & $<94$ & 28 & 0.03 \\
\hline $\mathrm{Pa}_{\mathrm{a}} \mathrm{O}_{2}$ after $\mathrm{HIT} \mathrm{kPa}$ & 0.80 & $0.58-1.00$ & $<6.8$ & 33 & 0.02 \\
\hline
\end{tabular}

The cut-off values and false-positive rates correspond to a sensitivity of $\geqslant 75 \%$. AUC: area under curve; $\mathrm{Cl}$ : confidence interval; MEF75: maximal expiratory flow when $75 \%$ of the forced vital capacity (FVC) remains to be exhaled; FEV1: forced expiratory volume in one second; MEF25: maximal expiratory flow when $25 \%$ of the FVC remains to be exhaled; $\mathrm{Sa}_{\mathrm{O}_{2}}$ : arterial oxygen saturation; HIT hypoxia inhalation test; \% pred: percentage of the predicted value. ${ }^{*}$ : the greater the AUC the better the predictive value of the baseline parameter (see fig. 1); for example, in the present population, six of 36 (sensitivity $84 \%$ ) patients with an FEV 1 of $<48 \%$ pred showed resting $\mathrm{Pa}_{\mathrm{a}_{2}}$ at altitude of $<6.6 \mathrm{kPa}$ whereas three of 36 patients (8.6\%) showed $\mathrm{Pa}_{\mathrm{a}} \mathrm{O}_{2}$ of $>6.6 \mathrm{kPa}$; ${ }^{\circ}$; FEV $1 / \mathrm{FVC}$.

episodes of hypoxaemia may have, especially in those subjects adapted to chronic hypoxaemia. It is noteworthy that patients with CF carry virtually no cardiovascular risk and are, on average, younger than chronic obstructive pulmonary disease patients.

The tolerance of adult patients with CF to hypoxic challenge was assessed in a laboratory at sea level and during exposure to high altitude in a mountain laboratory. This was carried

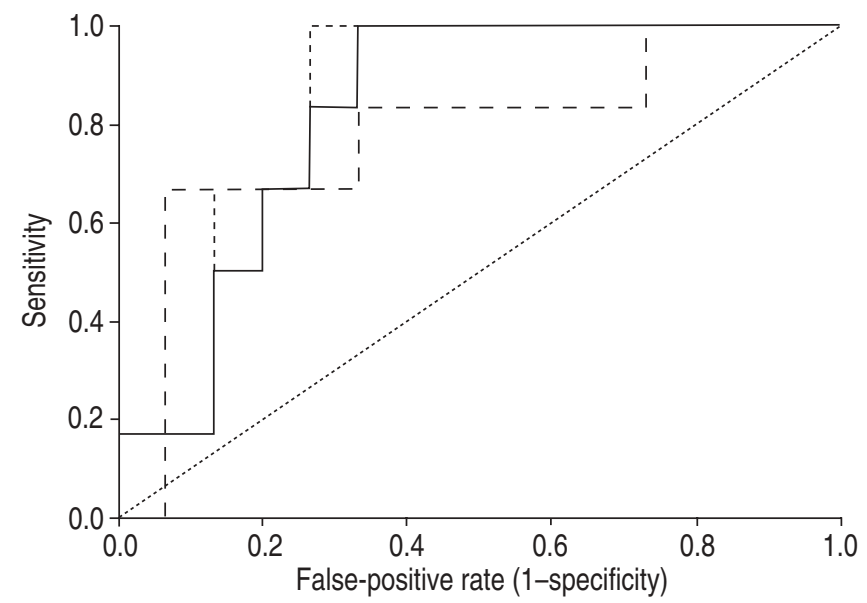

FIGURE 1. Receiver-operating characteristic curve comparing baseline arterial oxygen tension $\left(\mathrm{Pa}_{1} \mathrm{O}_{2} ;-\right)$, baseline forced expiratory volume in one second (\% pred; ----) and the result of the hypoxia inhalation test $\left(\mathrm{Pa}_{1} \mathrm{O}_{2}\right.$ after inhalation of a gas mixture with an inspiratory oxygen fraction of 0.15 for $15 \mathrm{~min}$; - - - ) for the prediction of mountain $\mathrm{Pa}, \mathrm{O}_{2}$ on arrival (cut-off $6.6 \mathrm{kPa}(50 \mathrm{mmHg}) ; \cdots \cdot \cdot$ : reference line). 


\begin{tabular}{|c|c|c|c|c|c|c|}
\hline \multirow[t]{2}{*}{ TABLE 5} & \multicolumn{6}{|c|}{$\begin{array}{l}\text { Comparison of different baseline parameters for } \\
\text { the prediction of an arterial oxygen tension }(\mathrm{Pa}, \mathrm{O} \\
\text { at altitude of }<6.6 \mathrm{kPa} \text { during moderate exercise } \\
\text { using receiver-operating characteristic curves }{ }^{\#}\end{array}$} \\
\hline & & AUC & $95 \% \mathrm{Cl}$ & $\begin{array}{l}\text { Cut-off } \\
\text { value }\end{array}$ & $\begin{array}{c}\text { False-positive } \\
\text { rate } \%\end{array}$ & $\mathrm{p}$-value \\
\hline \multicolumn{2}{|c|}{ MEF75 \% pred } & 0.93 & $0.82-1.04$ & $<58$ & 8 & 0.001 \\
\hline \multicolumn{2}{|c|}{ FEV 1 \% pred } & 0.93 & $0.82-1.04$ & $<67$ & 14 & 0.001 \\
\hline \multicolumn{2}{|c|}{ MEF25 \% pred } & 0.91 & $0.78-1.04$ & $<19$ & 25 & 0.002 \\
\hline \multicolumn{2}{|c|}{ Tiffeneau index } & 0.90 & $0.77-1.03$ & $<66$ & 17 & 0.003 \\
\hline \multicolumn{2}{|c|}{$\mathrm{Pa}_{\mathrm{a}} \mathrm{O}_{2}$ after $\mathrm{HIT} \mathrm{kPa}$} & 0.85 & $0.68-1.02$ & $<7.1$ & 28 & 0.009 \\
\hline \multicolumn{2}{|c|}{$\mathrm{Pa}_{\mathrm{a}, \mathrm{O}_{2}}$ baseline $\mathrm{kPa}$} & 0.85 & $0.66-1.03$ & $<9.9$ & 12 & 0.01 \\
\hline \multicolumn{2}{|c|}{$\mathrm{Sa}_{1} \mathrm{O}_{2}$ baseline $\%$} & 0.76 & $0.59-0.93$ & $<96$ & 33 & 0.016 \\
\hline
\end{tabular}

The cut-off values and false-positive rates correspond to a sensitivity of $\geqslant 75 \%$. AUC: area under curve; $\mathrm{Cl}$ : confidence interval; MEF75: maximal expiratory flow when $75 \%$ of the forced vital capacity (FVC) remains to be exhaled; FEV1: forced expiratory volume in one second; MEF25: maximal expiratory flow when $25 \%$ of the FVC remains to be exhaled; HIT: hypoxia inhalation test; $\mathrm{Sa}, \mathrm{O}_{2}$ : arterial oxygen saturation; \% pred: percentage of the predicted value. ${ }^{*}$ : the greater the AUC the better the predictive value of the baseline parameter (see fig. 2); ${ }^{`}:$ FEV $1 / F V C$

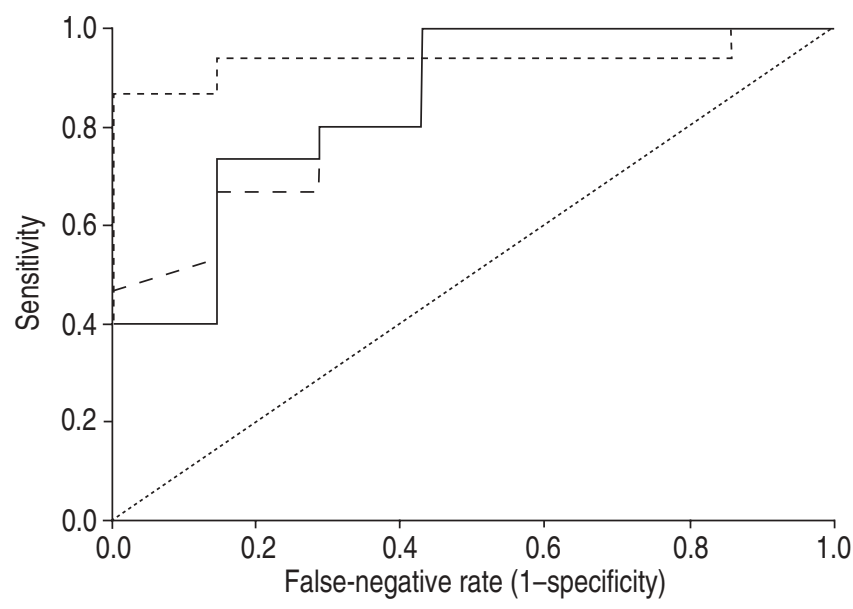

FIGURE 2. Receiver-operating characteristic curve comparing baseline arterial oxygen tension $\left(\mathrm{Pa}_{2} \mathrm{O}_{2} ;-\right)$, baseline forced expiratory volume in one second $(\%$ pred; ----) and the result of the hypoxia inhalation test $\left(\mathrm{Pa}_{\mathrm{a}} \mathrm{O}_{2}\right.$ after inhalation of a gas mixture with an inspiratory oxygen fraction of 0.15 for $15 \mathrm{~min}$; - - - ) for the prediction of mountain $\mathrm{Pa}_{\mathrm{a}} \mathrm{O}_{2}$ during moderate exercise (cut-off $6.6 \mathrm{kPa}(50 \mathrm{mmHg}$ ); $\therefore$ reference line)

out with the assumption that the results of an assessment performed in a mountain laboratory simulate what happens during flight. There is no doubt that patients on board an aircraft tend to remain in one position for long periods of time, that they may sleep and that the cabin atmosphere is dry. However, for technical and financial reasons, it is not feasible to measure lung function, blood gas levels or echocardiography during flight in a commercial aircraft. Therefore, hypoxic challenge at low altitude, hypobaric chamber exposure and exposure to high altitude are currently used to mimic in-flight conditions. During hypoxic challenge, patients tend to hyperventilate in response to desaturation, which may contribute to a false negative rate of desaturations [15]. Exposure in a hypobaric chamber provides a better simulation of in-flight conditions; however, it is not readily available, is not tolerated by all patients and is expensive. In addition, the humidity of chamber air reaches $100 \%$ during the evaluation time spent in the chamber. For both methods, the reported exposure times were shorter than the travel time in a commercial aircraft [11, 16-19].

Exposure to high altitude on a mountain was chosen because measurements of lung function and blood gas levels, echocardiography and exercise testing could be performed easily. Furthermore, the stay in a mountain laboratory can be extended for the duration of an international flight, $7 \mathrm{~h}$ in the present study. In order to improve the comparability of the present data to the in-flight situation, walking distances of $>150 \mathrm{~m}$ were not permitted. In addition, the subjects were encouraged to rest in a sitting position. Although a stay at a high-altitude laboratory is not fully comparable to a longdistance flight, the probability of underestimation of hypoxia is low due to the slightly higher altitude of the laboratory $(2,650 \mathrm{~m})$ compared to the minimum permitted cabin pressure, equivalent to an altitude of $2,438 \mathrm{~m}(8,000 \mathrm{ft})$ [1]. The difference in relative air humidity between aircraft and the mountain laboratory cannot account for differences in $\mathrm{Pa}, \mathrm{O}_{2}$, as inspired air is always saturated to $100 \%$ and the inspired oxygen tension of dry air is reduced by only $9.84 \mathrm{mmHg}$ at all altitudes.

Although the effects of altitude on lung function parameters were not the main issue of the present study, it was possible to compare both spirometric and body plethysmographic data at low and high altitude. In accordance with previously published results in healthy subjects, an increase in TLC, RV and ITGV, along with an increase in expiratory flow rates, was found [20-23]. This increase is probably due to the reduced gas density at 2,650 m compared to baseline $[22,24]$.

In contrast to others, an increase in FEV1 and FVC was found in the present subjects $[11,12,20,25,26]$. This could be due to the relatively short duration of stay at high altitude, as the typical reduction in FEV1 or FVC is seen in subjects with exposure to severe hypoxia $\left(\mathrm{Pa}_{1} \mathrm{O}_{2}<6.6 \mathrm{kPa}\right)$ for more than a few hours or with additional strenuous exercise [27].

The present results clearly indicate that the majority of $\mathrm{CF}$ patients adapted to chronically impaired lung function and hypoxia may tolerate $\mathrm{Pa}_{1} \mathrm{O}_{2}$ of $<6.6 \mathrm{kPa}(<50 \mathrm{mmHg})$ for several hours without clinically relevant symptoms at rest. Indeed, no patient showed any signs of cardiopulmonary decompensation when exposed to high altitude at rest.

The criterion of resting hypoxaemia of $6.6 \mathrm{kPa}$ as the lowest tolerable limit of in-flight hypoxaemia, used in current guidelines (ATS and BTS), might, therefore, be inadequate, at least for patients with CF adapted to chronic hypoxaemia $[3,4]$. This conclusion is supported by experiments in hypobaric chambers. Rose et al. [18] studied 10 CF patients in a hypobaric chamber for $1 \mathrm{~h}$ at pressures equivalent to altitudes of 2,000 and $3,000 \mathrm{~m}$. At 3,000 m, all but one subject exhibited hypoxaemia below the $6.6 \mathrm{kPa}$ limit. However, no subject 
experienced dyspnoea or cardiac symptoms. In another hypobaric chamber experiment, CHRISTENSEN et al. [16] demonstrated that mild exercise (at $30 \mathrm{~W}$ ) resulted in $\mathrm{Pa}_{1} \mathrm{O}_{2}$ of $<6.6 \mathrm{kPa}$ in 13 of 15 patients with chronic obstructive lung disease (baseline FEV1 $<50 \%$ pred; baseline $\mathrm{Pa}_{\mathrm{a}} \mathrm{O}_{2}>9.3 \mathrm{kPa}$ ), again without significant symptoms. Finally the study of NAUGHTON et al. [17] did not report any symptoms in chronic obstructive pulmonary disease patients with $\mathrm{Pa}_{1} \mathrm{O}_{2}$ as low as $3.9 \mathrm{kPa}(29 \mathrm{mmHg})$ at a simulated altitude of 2,438 $\mathrm{m}$ during mild exercise.

In the present investigation, mild exercise led to pronounced hypoxaemia in almost two-thirds of all patients. In one patient with severe pulmonary disease, light-headedness occurred as a sign of exercise intolerance using common criteria for exercise limitation [28]. The patient's baseline lung function was characterised by bronchial air flow limitation with a very low MEF25 (6\% pred) but relatively high resting $\mathrm{Pa}_{1} \mathrm{O}_{2}(9.4 \mathrm{kPa}$ $(71 \mathrm{mmHg}))$, which would make them eligible for air travel according to guidelines. However, during exercise at 2,650 m, this patient showed the lowest $\mathrm{Pa}_{\mathrm{a}_{2}} \mathrm{O}_{2}$ measured in the present study.

A synopsis of the few available data together with the data from the present investigation highlights the arbitrary nature of the $6.6 \mathrm{kPa}$ limit [4]. Although there is substantial uncertainty as to how to predict this value, air travel is denied or additional in-flight oxygen supply at high cost is recommended as a consequence [5].

The uncertainty as to how to predict the in-flight level of hypoxaemia is not fully resolved by the present data. However, the current study indicates that spirometric results may be more relevant than pre-flight $\mathrm{Sa}_{1} \mathrm{O}_{2}$ or $\mathrm{Pa}_{\mathrm{O}} \mathrm{O}_{2}$ as a predictor of in-flight oxygenation. The more obstructive patients are the more likely they are to become hypoxaemic at higher altitude [15]. Accordingly, an FEV1 of $<50 \%$ pred was associated with significantly lower $\mathrm{Pa}, \mathrm{O}_{2}$ both at rest and during exercise in the present $C F$ population $(p=0.002)$. The present authors would therefore suggest that spirometric results, e.g. FEV1, are included in future guidelines in order to emphasise the role of bronchial obstruction in a hypoxic environment.

The relatively poor predictive value of the pre-flight hypoxic challenge compared to spirometric results could be related to the more variable nature of $\mathrm{Pa}, \mathrm{O}_{2}$ measurements, which depend on ventilation, lung perfusion, bronchial obstruction, trapped air and other factors. Furthermore it is not possible to prevent a time delay between the HIT and air travel. The only study showing comparable results for $\mathrm{Pa}_{\mathrm{a}} \mathrm{O}_{2}$ after both high-altitude exposure and hypoxic challenge performed both measurements on the same day with a time interval of $<3 \mathrm{~h}$ [17].

For these reasons, it is not always possible to accurately predict high-altitude values on the basis of sea-level tests in a given individual patient.

\section{Conclusion}

The hope of young adult cystic fibrosis patients to travel by air should not be dismissed on the basis of official recommendations that were generated for a broad spectrum of lung diseases. In cystic fibrosis patients, the risk assessment of lower in-flight oxygenation should not be based solely on blood gas analysis, but should encompass the whole clinical situation of the patient, with special attention to the degree of airway obstruction.

\section{REFERENCES}

1 Federal Aviation Administration (US). Electronic Code of Federal Regulations. Title 14: Aeronautics and Space. Washington, DC, US Government Printing Office, 1986; Section 25.841. http:/ / ecfr.gpoaccess.gov/cgi/t/text/text$\mathrm{idx} ? \mathrm{c}=\mathrm{ecfr} \& \mathrm{sid}=54 \mathrm{f} 314 \mathrm{a} 8548 \mathrm{~b} 3153 \mathrm{c} 45 \mathrm{c} 813958 \mathrm{a} 89824 \& \mathrm{rgn}$ $=$ div8\&view $=$ text\&node $=14: 1 \cdot 0.1 \cdot 3 \cdot 10.4 \cdot 180.71 \& i d n o=14$. Date last updated: February 18 2004. Date last accessed: January 212005.

2 Cottrell JJ. Altitude exposures during aircraft flight. Flying higher. Chest 1988; 93: 81-84.

3 American Thoracic Society. Standards for the diagnosis and care of patients with chronic obstructive pulmonary disease (COPD) and asthma. Am Rev Respir Dis 1987; 136: 225-244.

4 British Thoracic Society Standards of Care Committee. Managing passengers with respiratory disease planning air travel: British Thoracic Society recommendations. Thorax 2002; 57: 289-304.

5 Stoller JK, Hoisington E, Auger G. A comparative analysis of arranging in-flight oxygen aboard commercial air carriers. Chest 1999; 115: 991-995.

6 American Thoracic Society. Standardization of Spirometry, 1994 Update. American Thoracic Society. Am J Respir Crit Care Med 1995; 152: 1107-1136.

7 Quanjer PH, Tammeling GJ, Cotes JE, Pedersen OF, Peslin R, Yernault JC. Lung volumes and forced ventilatory flows. Eur Respir J 1993; 6: Suppl. 16, 5-40.

8 Berger M, Haimowitz A, Van Tosh A, Berdoff RL, Goldberg E. Quantitative assessment of pulmonary hypertension in patients with tricuspid regurgitation using continuous wave Doppler ultrasound. J Am Coll Cardiol 1985; 6: 359-365.

9 Roach RC, Bärtsch P, Oelz O, Hackett PH. The Lake Louise acute mountain sickness scoring system. In: Sutton JR, Houston CS, Coates G, eds. Hypoxia and Mountain Medicine. Burlington, VT, Queen City Press, 1993; pp. 272-274.

10 Zweig MH, Campbell G. Receiver-operating characteristic (ROC) plots: a fundamental evaluation tool in clinical medicine. Clin Chem 1993; 39: 561-577.

11 Thews O, Fleck B, Kamin WE, Rose DM. Respiratory function and blood gas variables in cystic fibrosis patients during reduced environmental pressure. Eur J Appl Physiol 2004; 92: 493-497.

12 Hashimoto F, McWilliams B, Qualls C. Pulmonary ventilatory function decreases in proportion to increasing altitude. Wilderness Environ Med 1997; 8: 214-217.

13 Jardin F, Dubourg O, Bourdarias JP. Echocardiographic pattern of acute cor pulmonale. Chest 1997; 111: 209-217.

14 Crockett AJ, Cranston JM, Moss JR, Alpers JH. Domiciliary oxygen for chronic obstructive pulmonary disease. Cochrane Database Syst Rev 2000; 4: CD001744.

15 Buchdahl RM, Babiker A, Bush A, Cramer D. Predicting hypoxaemia during flights in children with cystic fibrosis. Thorax 2001; 56: 877-879. 
16 Christensen CC, Ryg M, Refvem OK, Skjonsberg OH. Development of severe hypoxaemia in chronic obstructive pulmonary disease patients at 2,438 $\mathrm{m}(8,000 \mathrm{ft})$ altitude. Eur Respir J 2000; 15: 635-639.

17 Naughton MT, Rochford PD, Pretto JJ, Pierce RJ, Cain NF, Irving LB. Is normobaric simulation of hypobaric hypoxia accurate in chronic airflow limitation? Am J Respir Crit Care Med 1995; 152: 1956-1960.

18 Rose DM, Fleck B, Thews O, Kamin WE. Blood gasanalyses in patients with cystic fibrosis to estimate hypoxemia during exposure to high altitudes in a hypobaric-chamber. Eur J Med Res 2000; 5: 9-12.

19 Dillard TA, Moores LK, Bilello KL, Phillips YY. The preflight evaluation. A comparison of the hypoxia inhalation test with hypobaric exposure. Chest 1995; 107: 352-357.

20 Welsh CH, Wagner PD, Reeves JT, et al. Operation Everest. II: spirometric and radiographic changes in acclimatized humans at simulated high altitudes. Am Rev Respir Dis 1993; 147: 1239-1244.

21 Mansell A, Powles A, Sutton J. Changes in pulmonary PV characteristics of human subjects at an altitude of 5,366 m. J Appl Physiol 1980; 49: 79-83.
22 Coates G, Gray G, Mansell A, et al. Changes in lung volume, lung density, and distribution of ventilation during hypobaric decompression. J Appl Physiol 1979; 46: 752-755.

23 Dramise JG, Consolazio CF, Johnson HL. Changes in pulmonary volumes with relocation to $1,600 \mathrm{~m}$ following acute translocation to $4,300 \mathrm{~m}$. Aviat Space Environ Med 1976; 47: 261-264.

24 Mink SN, Wood LD. How does $\mathrm{HeO}_{2}$ increase maximum expiratory flow in human lungs? J Clin Invest 1980; 66: 720-729.

25 Mason NP, Barry PW, Pollard AJ, et al. Serial changes in spirometry during an ascent to $5,300 \mathrm{~m}$ in the Nepalese Himalayas. High Alt Med Biol 2000; 1: 185-195.

26 Rupwate RU, Chitaley M, Kamat SR. Cardiopulmonary functional changes in acute acclimatisation to high altitude in mountaineers. Eur J Epidemiol 1990; 6: 266-272.

27 Cremona G, Asnaghi R, Baderna P, et al. Pulmonary extravascular fluid accumulation in recreational climbers: a prospective study. Lancet 2002; 359: 303-309.

28 American Thoracic Society, American College of Chest Physicians. ATS/ACCP Statement on cardiopulmonary exercise testing. Am J Respir Crit Care Med 167: 211-277. 